WagenaAR, W. A., \& SAGaria, S. (1975). Misperception of exponential growth. Perception \& Psychophysics, 18, 416-422.

WagenaAr, W. A., \& Timmers, H. (1978). Extrapolation of exponential time series is not enhanced by having more data points. Perception \& Psychophysics, 24, 182-184.

\section{NOTE}

1. The least squares quadratic here is $0.2025 \mathrm{x}^{2}-0.2235 \mathrm{x}+0.6425$. It yields values for $x=1$ to 4 of $\$ 0.62, \$ 1.01, \$ 1.79$, and $\$ 2.99$, respectively.

(Manuscript received June 15, 1984;

accepted for publication June 25, 1984.)

\title{
ANNOUNCEMENT \\ Third European Conference on Eye Movements (ECEM3) September 24-27, 1985, Dourdan (near Paris), France
}

The Third European Conference on Eye Movements will be held at Dourdan, near Paris, France, September 24-27, 1985. Its aim is to confront work being done in different fields (psychology, physiology, neuropsychology, ophthalmology, engineering, artificial intelligence, ergonomics, pathology, development, education) concerning the functions, capacities, and limitations of the visual system at work through its mobility. Specialized symposia will be held on topics concerning, among others, oculomotor control, eye movements in perception and reading, and eye movements as a tool in ergonomics.

Abstracts for the conference are due in March 1985. For further information, please contact the organizers: Ariane Lévy-Schoen and Kevin O'Regan, Groupe Regard, Laboratoire de Psychologie Expérimentale, 28 rue Serpente, 75006 Paris, France. 